\title{
不同材料覆盖的土壤水温效应及对玉米生长的影响
}

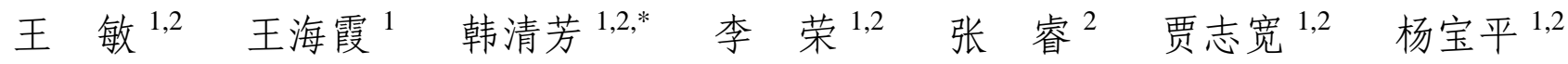

${ }^{1}$ 西北农林科技大学中国旱区节水农业研究院 / 农业部旱地作物生产与生态重点开放实验室; ${ }^{2}$ 西北农林科技大学农学院, 陕西杨凌 712100

摘 要: 在渭北旱塬区采用随机区组试验, 对比研究了生物降解膜 $(S)$ 、塑料地膜 $(D)$ 、秸秆 $(J)$ 、液态膜 $(Y)$ 覆盖和裸 地平作种植玉米的土壤水温效应及玉米生长状况。结果表明, 玉米进入抽雄期和灌浆期后, 不同覆盖材料间土壤水分 出现较大差异, 40 160 $\mathrm{cm} \mathrm{J}$ 覆盖土壤平均含水量显著 $(P<0.05)$ 高于对照和其他覆盖; $\mathrm{S}$ 和 $\mathrm{D}$ 覆盖对较深土层 $(60 \sim 120$ $\mathrm{cm}$ )的水分利用加强。 $\mathrm{J}$ 覆盖保墑效果好于其他处理, 玉米生长前期主要提高 $0 \sim 100 \mathrm{~cm}$ 土壤含水量, 后期提高 100 200 $\mathrm{cm}$ 土壤含水量; $\mathrm{S}$ 和 $\mathrm{D}$ 覆盖的保墑效果主要表现在玉米营养生长阶段的浅层土壤。玉米营养生长阶段 $5 \sim 25 \mathrm{~cm}$ 平均 地温, $\mathrm{S}$ 和 $\mathrm{D}$ 覆盖分别提高 $1.4^{\circ} \mathrm{C}$ 和 $2.6^{\circ} \mathrm{C}, \mathrm{J}$ 和 $\mathrm{Y}$ 覆盖分别降低 $3.0^{\circ} \mathrm{C}$ 和 $0.8^{\circ} \mathrm{C} 。 \mathrm{~S}$ 和 $\mathrm{D}$ 覆盖水温协同, 延长了玉米营 养生长时间, 使玉米全生育期提前 $11 \mathrm{~d}, \mathrm{~J}$ 覆盖由于降低地温使全生育期延长 $3 \mathrm{~d}$, 液态膜不影响生育进程。 $\mathrm{S}$ 和 $\mathrm{D}$ 覆 盖显著 $(P<0.05)$ 提高了玉米穗长、穗粗和行粒数及地上部干重, $\mathrm{Y}$ 覆盖显著 $(P<0.05)$ 增加玉米的百粒重, $\mathrm{J}$ 覆盖显著 $(P<0.05)$ 降低了玉米穗长、行粒数和百粒重。 4 种覆盖均不同程度降低了玉米的经济系数, S、D 和 $\mathrm{Y}$ 覆盖玉米分别增 产 26.9\% ( $P<0.05) 、 34.7 \%(P<0.05)$ 和 2.4\%, J 覆盖造成玉米减产 $10.5 \%$ 。

关键词: 玉米; 不同材料; 覆盖; 水; 温度; 生长

\section{Effects of Different Mulching Materials on Soil Water, Temperature, and Corn Growth} WANG Min ${ }^{1,2}$, WANG Hai-Xia ${ }^{1}$, HAN Qing-Fang ${ }^{1,2, *}$, LI Rong ${ }^{1,2}$, ZHANG Rui $^{2}$, JIA Zhi-Kuan ${ }^{1,2}$, and YANG
Bao-Ping

\footnotetext{
${ }^{1}$ Chinese Research Institute of Water-saving Agriculture in Dry Area, Northwest A\&F University / Key Laboratory of Crop Production and Ecology, Ministry of Agriculture, Yangling 712100 China; ${ }^{2}$ College of Agronomy, Northwest A\&F University, Yangling 712100, China
}

\begin{abstract}
The study, with randomized block design, measured the effects of different mulching materials which included biodegradable film (S), plastic film (D), corn straw (J), liquid film (Y) and bare land on soil water, temperature and corn growth in Weibei rainfed tableland, which would be as the basis of mulching cultivation in this area. The results showed that soil moisture in different mulchings showed different characteristics after heading and filling stage of corn, soil average moisture $(40-60 \mathrm{~cm})$ of $\mathrm{J}$ mulching was evidently $(P<0.05)$ higher than that of control treatment and other mulchings; water deprivation of $\mathrm{S}$ and $\mathrm{D}$ mulchings were improved in the deeper soil layers $(60-120 \mathrm{~cm})$. Soil water retention of J mulching was better than that of other treatments, J mulching mainly improved the soil moisture in 0-100 cm layer before heading stage, and in 100-200 cm layer after heading stage; S and D mulchings mainly improved the soil moisture in shallower layer before heading stage. The average soil temperature in $5-25 \mathrm{~cm}$ soil layer before heading stage increased $1.4^{\circ} \mathrm{C}, 2.6^{\circ} \mathrm{C}$ in $\mathrm{S}$ and $\mathrm{D}$ treatments and brought down $3.0^{\circ} \mathrm{C}, 0.8^{\circ} \mathrm{C}$ in $\mathrm{J}$ and $\mathrm{Y}$ treatments respectively. S and $\mathrm{D}$ mulchings extended the vegetative growth under the effect of water and temperature increment, and advanced 11 days of whole growing period, while J mulching extended 3 days of growth period, there was no effect on whole growing period in Y mulching. S and D mulchings evidently $(P<0.05)$ increased ear length, ear diameter, kernels per row and dry biomass of shoot; Y mulching evidently $(P<0.05)$ increased hundred-kernel weight; $\mathrm{J}$ mulching evidently $(P<0.05)$ decreased ear length, kernels per row and hundred-kernel weight. Four mulchings reduced economical coefficient of corn to a different extent. S, D, and Y mulchings respectively increased yield by $26.9 \%(P<0.05), 34.7 \%(P<0.05)$, and $2.4 \%$, J mulching decreased yield by $10.5 \%$.
\end{abstract}

Keywords: Corn; Different materials; Mulching; Water; Temperature; Growth

本研究由国家“十一五”科技支撑计划项目(2006BAD29B03)资助。

* 通讯作者(Corresponding author): 韩清芳, E-mail: hanqf88@126.com, Tel: 029-87080168

第一作者联系方式: E-mail: minwang@nwsuaf.edu.cn

Received(收稿日期): 2010-12-20; Accepted(接受日期): 2011-03-27. 
在降雨偏少的北方旱作农区，农田地面覆盖可 以有效减少土壤水分的无效蒸发, 提高作物水分利 用效率。目前生产应用的覆盖材料主要包括塑料地 膜、生物降解膜、作物秸秆、液态膜等。研究表明, 在 黄土高原旱作区, 地膜覆盖使玉米生育前期 $0 \sim 25 \mathrm{~cm}$ 土层的日平均温度比对照提高 $2.2 \sim 3.0^{\circ} \mathrm{C}, 0 \sim 10 \mathrm{~cm}$ 土层的含水量比露地增加 $18.84 \%$, 玉米籽粒产量比 对照增产 $19.16 \%{ }^{[1]}$ 。在东北北部和东部积温不足的 地区, 玉米地膜覆盖增产率达 35\% 55\%左右 ${ }^{[2]}$ 。地膜 覆盖技术由于具有增温、保墒、调水等效果, 可以 大幅度提高作物的经济产量 ${ }^{[3]}$ 。为了减少地膜覆盖 产生的土壤环境污染问题而开发的降解膜覆盖种植 也具有保温作用, 利于增产 ${ }^{[4]}$ 。由 $30 \%$ 淀粉、 $50 \%$ PCL (聚己内酯)及助剂组成的降解膜在玉米生长的 3 个时段土壤均温分别为 $25.80^{\circ} \mathrm{C} 、 32.24^{\circ} \mathrm{C}$ 和 $29.53^{\circ} \mathrm{C}$, 保温效果与普通地膜相当 ${ }^{[5]}$ 。玉米苗期和拔节期用 降解地膜覆盖可使土壤咜水量比裸地增加 3 倍和 1 倍 ${ }^{[6]}$ 。对环境的日益关注使秸秆覆盖技术在农业生 产中得到重视。秸秆覆盖可以改善土壤结构, 增加 降水入渗, 减少地表径流, 抑制土壤蒸发, 降低土 壤水分和养分流失, 并随着覆盖秸秆的腐烂还田, 土壤水、肥、气、热得到有效调节 ${ }^{[7]}$ 。整秸秆覆盖 处理的土壤水分咜存量平均可较半秸秆覆盖多 12.7 $\mathrm{mm}$, 比传统无覆盖多咜存水分 $28.4 \mathrm{~mm}^{[8]}$ 。液态膜 是近年开发的新型覆盖材料, 能够直接地面喷雾成 膜, 具有使用方便的特点, 能使夏玉米有效抵抗干 旱逆境而达到增产的效果, 显著提高经济效益, 低 水分处理下液膜覆盖增产率达到 $56.97 \%$, 产投比为 $1.695^{[9]}$ 。本文通过对比研究揭示不同覆盖材料调节 土壤环境和影响作物生长的生理生态差异, 以为旱
地覆盖节水栽培的研究和生产应用提供理论依据。

\section{1 材料与方法}

\section{1 试验地概况}

陕西省渭南市合阳县甘井镇西北农林科技大学 旱作试验区海拔 $910 \mathrm{~m}$, 年日照时数 $2528.3 \mathrm{~h}$, 年均 温度 $10.5^{\circ} \mathrm{C}$, 无霜期 $169 \sim 180 \mathrm{~d}$ 。多年平均降雨量 580 $\mathrm{mm}$, 主要集中在 7 9 月, 气候干旱, 年蒸发量 1832.8 $\mathrm{mm}$, 土壤为塿土。0 20 cm 土壤含有机质 $13.95 \mathrm{~g}$ $\mathrm{kg}^{-1}$ 、全氮 $0.87 \mathrm{~g} \mathrm{~kg}^{-1}$ 、全磷 $0.63 \mathrm{~g} \mathrm{~kg}^{-1}$ 、全钾 $9.63 \mathrm{~g}$ $\mathrm{kg}^{-1}$ 、碱解氮 $79.80 \mathrm{mg} \mathrm{kg}^{-1}$ 、速效磷 $24.88 \mathrm{mg} \mathrm{kg}^{-1}$ 、 速效钾 $123.50 \mathrm{mg} \mathrm{kg}^{-1}, \mathrm{pH}$ 8.1。2009 年全生育期降 雨量见表 1 。

\section{2 试验材料}

供试玉米品种为豫玉 22。覆盖材料分别为塑料 地膜(山西运城塑料厂生产)、生物降解膜(陕西华宇 高科生物有限公司生产)、玉米秸秆(上一年收获)和 液态膜(北京金尚禾生物科技有限公司生产)。

\section{3 试验设计}

设裸地平作 $(\mathrm{CK})$ 、塑料地膜覆盖 $(\mathrm{D}) 、$ 生物降解 膜覆盖 $(S)$ 、玉米秸秆覆盖 $(J) 、$ 液态膜覆盖 $(Y) 5$ 个处 理, 不同材料均为平作全田覆盖。玉米种植行距 60 $\mathrm{cm}$, 株距 $30 \mathrm{~cm}$ 。覆盖前机械旋耕, D 和 S 处理覆盖 后点播; $\mathrm{J}$ 和 $\mathrm{Y}$ 处理点播后立即覆盖, $\mathrm{J}$ 处理秸秆覆盖 量为 $9000 \mathrm{~kg} \mathrm{hm}^{-2}$, 液态膜用量为 $1500 \mathrm{~kg} \mathrm{hm}^{-2}$, 使 用喷雾器均匀喷酒。随机区组设计, 3 个重复。小区 面积 $20.16 \mathrm{~m}^{2}$, 施纯氮 $300 \mathrm{~kg} \mathrm{hm}^{-2}$ (50\%播前基施, $50 \%$ 大喇叭口期使用手动点播器进行定量追施), $\mathrm{P}_{2} \mathrm{O}_{5} 150 \mathrm{~kg} \mathrm{hm}^{-2}, \mathrm{~K}_{2} \mathrm{O} 150 \mathrm{~kg} \mathrm{hm}^{-2}$, 磷、钾肥均播前 施入。覆盖前对所有处理喷酒除草剂，玉米生长期

表 1 全生育期降雨量

Table 1 Precipitation in the whole growing period

\begin{tabular}{|c|c|c|c|c|c|c|c|}
\hline \multirow{2}{*}{$\begin{array}{c}\text { 处理 } \\
\text { Treatment }\end{array}$} & \multicolumn{7}{|c|}{ 降雨量 Precipitation (mm) } \\
\hline & 4 月 Apr. & 5 月 May & 6 月 Jun. & 7 月 Jul. & 8 月 Aug. & 9 月 Sep. & 合计 Total \\
\hline \multicolumn{8}{|l|}{ 总降雨量 Whole precipitation } \\
\hline 裸地和液膜 CK and Y & 7.1 & 136.5 & 46.8 & 46.7 & 96.8 & 39.6 & 373.5 \\
\hline 地膜和生膜 D and S & 7.1 & 136.5 & 46.8 & 46.7 & 96.8 & 2.8 & 336.7 \\
\hline 秸秆 J & 7.1 & 136.5 & 46.8 & 46.7 & 96.8 & 52.4 & 386.3 \\
\hline \multicolumn{8}{|c|}{ 有效降雨量 Effective precipitation } \\
\hline 裸地和液膜 CK and Y & 7.1 & 132.1 & 42.6 & 38.7 & 87.6 & 30.2 & 338.3 \\
\hline 地膜和生膜 D and S & 7.1 & 132.1 & 42.6 & 38.7 & 87.6 & 0 & 308.1 \\
\hline 秸秆 J & 7.1 & 132.1 & 42.6 & 38.7 & 87.6 & 43.0 & 351.1 \\
\hline
\end{tabular}

裸地：裸地平作；液膜：液态膜覆盖；地膜：塑料地膜覆盖；生膜：生物降解膜覆盖；秸秆：玉米秸秆覆盖。

CK: bare land; Y: liquid film mulching; D: plastic film mulching; S: biodegradable film mulching; J: corn straw mulching. 
人工除草, 无灌溉。2 009 年 4 月 26 日播种, D 处理 和 S 处理于 2009 年 9 月 7 日成熟收获; Y 处理和 CK 于 2009 年 9 月 18 日成熟收获; $J$ 处理于 2009 年 9 月 21 日成熟收获。

\section{4 测定项目及方法}

采用土钻取样烘干法, 每 $20 \mathrm{~cm}$ 取一个样, 测 0 200 cm 土壤含水量。以金属曲管地温计 5 支一组, 分别测定 5、10、15、20 和 $25 \mathrm{~cm}$ 土层地温。另测 玉米地上部干重、籽粒产量、生物产量、穗长、穗 粗、穗行数、行粒数、百粒重等。采用 Microsoft Excel 2003 和 DPSv7.05 软件进行数据处理。

\section{2 结果与分析}

\section{1 不同材料覆盖对土壤水分的影响}

2.1.1 对土壤䇄水量的影响 分析渭北旱塬玉米 生长期的土壤水分动态, 不覆盖种植的土壤咜水量 表现为负增长, 即玉米生育期耗水量大于降雨量(表 2)。玉米成熟期, S 处理和 D 处理两种覆盖下作物的 快速生长增加了其对土壤水分的消耗, 土壤咜水量 均显著 $(P<0.05)$ 低于 $\mathrm{CK}$ 。相比之下, $\mathrm{J}$ 处理下作物生 长缓慢, 土壤㲸水量显著 $(P<0.05)$ 高于 $\mathrm{CK} ; \mathrm{Y}$ 处理下 作物生长速度与对照相当, 土壤咜水量略高于 $\mathrm{CK}$ 。 和播种期基础水分相比, $\mathrm{S}$ 处理和 $\mathrm{D}$ 处理土壤䛎水量 均显著 $(P<0.05)$ 低于播种期基础, $\mathrm{J}$ 处理和 $\mathrm{Y}$ 处理均 略高于播种期, 秸秆和液态膜覆盖有利于土壤水分 的可持续利用。

表 2 不同材料覆盖下 0 $200 \mathrm{~cm}$ 土壤㙃水量

Table 2 Soil water retaining in $0-200 \mathrm{~cm}$ layer of soil in different mulching treatments

\begin{tabular}{ccc}
\hline \multirow{2}{*}{$\begin{array}{c}\text { 处理 } \\
\text { Treatment }\end{array}$} & \multicolumn{2}{c}{ 土壤咜水量 Soil water retaining $(\mathrm{mm})$} \\
\cline { 2 - 3 } & 播种期 Sowing & 成熟期 Maturing \\
\hline 地膜 $\mathrm{D}$ & $433.07 \pm 7.54 \mathrm{ab}$ & $369.31 \pm 3.99 \mathrm{c}$ \\
生膜 $\mathrm{S}$ & $433.07 \pm 7.54 \mathrm{ab}$ & $380.65 \pm 9.87 \mathrm{c}$ \\
裸地 $\mathrm{CK}$ & $433.07 \pm 7.54 \mathrm{ab}$ & $426.20 \pm 3.57 \mathrm{~b}$ \\
液膜 $\mathrm{Y}$ & $433.07 \pm 7.54 \mathrm{ab}$ & $438.61 \pm 9.54 \mathrm{ab}$ \\
秸秆 $\mathrm{J}$ & $433.07 \pm 7.54 \mathrm{ab}$ & $454.52 \pm 6.47 \mathrm{a}$ \\
\hline
\end{tabular}

不同小写字母表示 $P<0.05$ 水平的差异显著性, 数据为平均 值土标准差, 重复 3 次。缩写同表 1 。

Values followed by the different letters are significantly different at $P<0.05$, the data: mean $\pm S D$, three replications. Abbreviations as in Table 1.

\subsection{2 对土壤含水量动态的影响 如图 1, 玉米} 播前 0 200 cm 基础土壤含水量在 14.15\% 17.98\%之 间, 在 180 200 cm 土层最高, 80 100 cm 最低。出苗 期, 由于少量降雨 $(7.1 \mathrm{~mm})$ 补充, 0 140 cm 土壤含水
量较播前提高。0 100 cm, 覆盖处理均高于 $\mathrm{CK}$ 。 0 40 cm, 各处理土壤平均含水量为 $\mathrm{J}$ 处理 $>\mathrm{S}$ 处理 $>\mathrm{Y}$ 处理 $>\mathrm{D}$ 处理 $>\mathrm{CK}$, 覆盖处理均显著 $(P<0.05)$ 高于 $C K$ 。在耕层 $20 \mathrm{~cm}$ 处理间的差异主要表现为 $S$ 和 $Y$ 处理显著 $(P<0.05)$ 高于 $\mathrm{D}$ 处理, $\mathrm{J}$ 处理显著 $(P<0.05)$ 高于 $\mathrm{D}$ 处理。拔节期, 随着玉米根系的生长, 对土 壤浅层水分消耗较大, $0 \sim 40 \mathrm{~cm}$, 各处理土壤平均含 水量为 $\mathrm{J}$ 处理 $>\mathrm{Y}$ 处理 $>\mathrm{S}$ 处理 $>\mathrm{D}$ 处理 $>\mathrm{CK}$, 秸秆覆 盖的保墑作用明显, 高出对照 $1.16 \%$ 。40 80 cm, 各 覆盖处理之间及与对照土壤含水量均无明显差异。 $100 \sim 200 \mathrm{~cm}$, 覆盖处理均高于 CK, D 处理显著 $(P<$ 0.05)高于 $\mathrm{CK}$ 。

大喇叭口期, 玉米迅速生长, 各处理浅层土壤 含水量与拔节期相比明显降低, 0 60 cm 土壤平均含 水量显著 $(P<0.05)$ 低于播前土壤含水量, $\mathrm{J}$ 处理显著 $(P<0.05)$ 高于 $\mathrm{CK}$ 和其他覆盖处理。受生育前期地温 影响, 植株相对弱小, 对土壤水分的吸收消耗少于 其他处理, 这可能是秸秆覆盖下土壤含水量高的主 要原因。60 140 cm, J 处理土壤平均含水量显著 $(P<0.05)$ 高于 $\mathrm{CK}$ 和其他覆盖处理, $\mathrm{J}$ 处理和 CK 均显 著 $(P<0.05)$ 高于其他覆盖处理。抽雄期, 随着玉米生 长的进一步消耗, 各处理 $80 \mathrm{~cm}$ 以上土层土壤含水 量均低于播种期, 且不同处理间 $40 \mathrm{~cm}$ 以下土壤含 水量出现较大差异。40 160 cm, J 处理土壤平均含水 量显著 $(P<0.05)$ 高于 $\mathrm{CK}$ 和其他覆盖处理, $\mathrm{S}$ 和 $\mathrm{D}$ 处 理接近, 始终低于对照, $\mathrm{Y}$ 处理和对照差异不大。 60 120 cm 土壤平均含水量为 $\mathrm{J}$ 处理 $>\mathrm{CK}>\mathrm{Y}$ 处理 $>\mathrm{S}$ 处理 $>\mathrm{D}$ 处理, $\mathrm{S}$ 处理和 $\mathrm{D}$ 处理土壤含水量明显低于 大喇叭口期, 说明这两种处理下玉米生长消耗加快, 对较深土层的水分利用加强。相比之下, $\mathrm{J}$ 处理仅 40 80 cm 土壤含水量明显低于大喇叭口期, 说明秸 秆覆盖下玉米生长消耗水相对滞缓。

灌浆期, 40 200 cm 土壤平均含水量为 $\mathrm{J}$ 处理 $>\mathrm{Y}$ 处理 $>C K>S$ 处理 $>D$ 处理。秸秆覆盖的保墑效果仍 好于其他处理。成熟期, 由于降雨的补充, 各处理 0 40 $\mathrm{cm}$ 土壤含水量较灌浆期有了较大幅度的提高, 并高于播种期。0 200 cm, S 处理和 D 处理土壤含水 量均小于其他处理, 可能的原因是较高的地温导致 玉米植株叶片的蒸腾加强, 增加了土壤水分的消 耗。 $80 \sim 180 \mathrm{~cm}$ 土壤平均含水量为 $\mathrm{J}$ 处理 $>\mathrm{Y}$ 处理 $>\mathrm{CK}>\mathrm{S}$ 处理 $>\mathrm{D}$ 处理。

全生育期内, $\mathrm{J}$ 处理 $0 \sim 200 \mathrm{~cm}$ 土壤平均含水量 高于其他各处理, 且在大喇叭口期、抽雄期和灌浆 
期显著高于其他各处理, 说明秸秆覆盖的保墒效果 好于其他 3 种材料, 尤其表现在生育中后期。相比 之下, $\mathrm{D}$ 和 $\mathrm{S}$ 处理在大喇叭口期之后的平均含水量显 著低于 $\mathrm{J}$ 处理, 可能的原因是玉米在生育前期的迅

Soil moisture (\%)

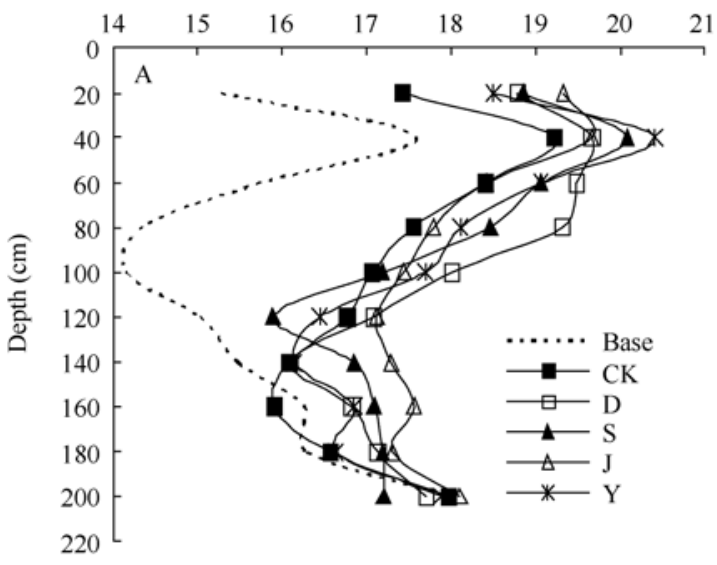

Soil moisture (\%)

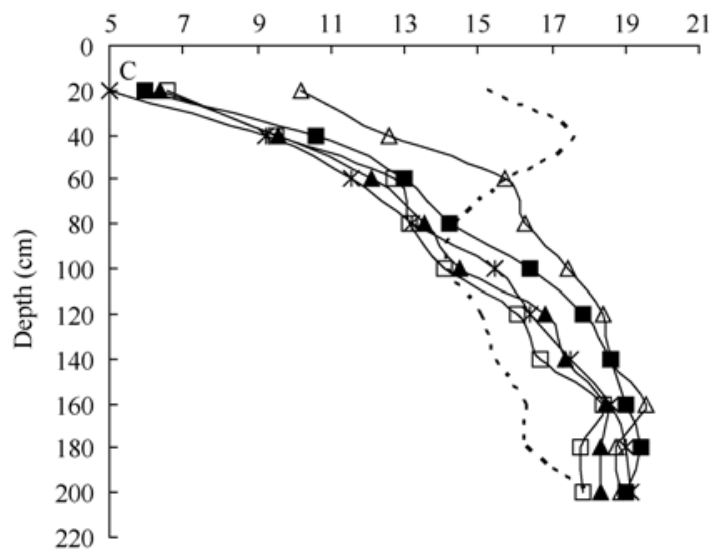

Soil moisture (\%)

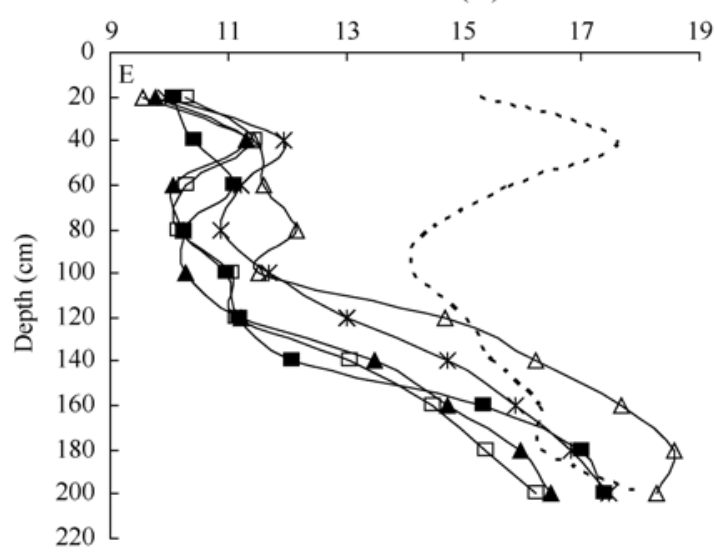

速生长及覆盖的增温作用同时增加了大喇叭口期及 其之后的植株蒸腾, 消耗了大量的土壤水分。Y 处 理在大喇叭口期之前和之后的平均含水量均高于 CK，说明液态膜覆盖具有一定保墒作用，而该处理

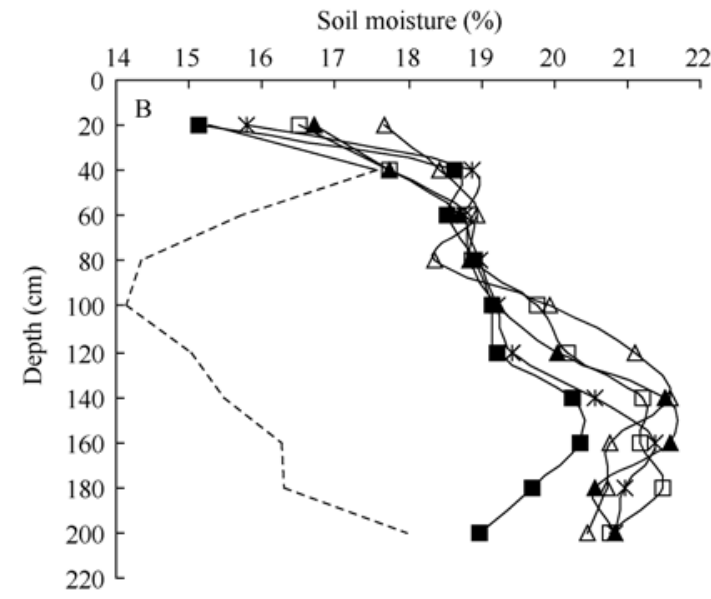

Soil moisture (\%)



Soil moisture (\%)

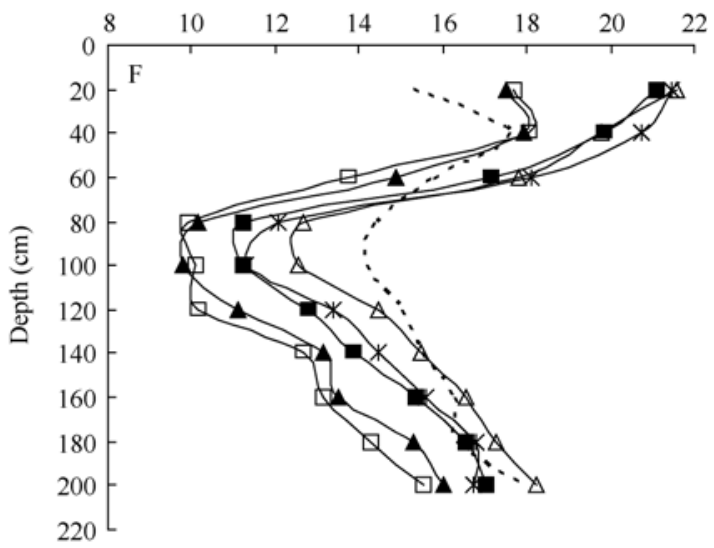

图 1 不同材料覆盖玉米各生育时期 $0 \sim 200 \mathrm{~cm}$ 分层土壤含水量动态变化

Fig. 1 Soil moisture content in $0-200 \mathrm{~cm}$ soil layer in different mulching treatments in each development stage A：出苗期; B：拔节期; C：大喇叭口期; D：抽雄期; E：灌浆期; F：成熟期。Base：播前基础; CK：裸地平作; D：塑料地膜覆盖; $\mathrm{S}:$ 生物降解膜覆盖; J: 玉米秸秆覆盖; Y: 液态膜覆盖。

A: emerging; B: jointing; C: bell-mouthing; D: heading; E: filling; F: maturing. Base: sowing; CK: bare land; D: plastic film mulching; S: biodegradable film mulching; J: corn straw mulching; Y: liquid film mulching. 




图 2 不同材料覆盖玉米各生育时期 $0 \sim 200 \mathrm{~cm}$ 土壤平均含水量变化

Fig. 2 Average moisture content in 0-200 cm soil layer in different mulching treatments in each development stage A：出苗期; B：拔节期; C: 大喇叭口期; D：抽雄期; E：灌浆期; F：成熟期。Base：播前基础; CK：裸地平作; D: 塑料地膜覆盖; $\mathrm{S}:$ 生物降解膜覆盖; J: 玉米秸秆覆盖; Y: 液态膜覆盖。

A: emerging; B: jointing; C: bell-mouthing; D: heading; E: filling; F: maturing. Base: sowing; CK: bare land; D: plastic film mulching; S: biodegradable film mulching; J: corn straw mulching; Y: liquid film mulching.

在大喇叭口期低于 $\mathrm{CK}$ 的原因可能是拔节期到大喇 叭口期玉米的快速生长消耗水分增加。

\section{2 对地温和玉米生育进程的影响}

地温是影响玉米种子出苗的重要因素。播种期、 出苗期和拔节期全天 5 25 cm 平均地温(图 3) S 和 D 处理均明显高于 CK, S 处理较 D 处理低, $\mathrm{Y}$ 处理略低 于 $\mathrm{CK}, \mathrm{J}$ 处理显著 $(P<0.05)$ 低于 $\mathrm{CK}$ 。 $\mathrm{D}$ 和 $\mathrm{S}$ 处理播 种期 5 25 cm 日平均地温分别较 CK $\left(22.1^{\circ} \mathrm{C}\right)$ 高 2.2 ${ }^{\circ} \mathrm{C}$ 和 $1.6^{\circ} \mathrm{C}$, 通过提高玉米生长前期(图 4)的地温缩 短出苗时间, 而 $\mathrm{J}$ 处理较 $\mathrm{CK}$ 低 $3.7^{\circ} \mathrm{C}, \mathrm{Y}$ 处理比 $\mathrm{CK}$ 仅低 $0.5^{\circ} \mathrm{C}$ 。出苗期 $\mathrm{D}$ 和 $\mathrm{S}$ 处理的地温分别为 25.7 ${ }^{\circ} \mathrm{C}$ 和 $24.6^{\circ} \mathrm{C}$, 较 $\mathrm{CK}$ 高 $3.2^{\circ} \mathrm{C}$ 和 $2.1^{\circ} \mathrm{C}$, 出苗时间均比 $\mathrm{CK}$ 提前 $3 \mathrm{~d} ; \mathrm{J}$ 和 $\mathrm{Y}$ 处理分别较 $\mathrm{CK}$ 低 $3.3^{\circ} \mathrm{C}$ 和 $1.5^{\circ} \mathrm{C}$ 。 与其他覆盖处理相比, $\mathrm{J}$ 处理在播种期和出苗期明显 降低了 5 25 cm 地温, 造成出苗晚于 CK, 且植株弱 小, 严重影响了玉米的前期生长。 $\mathrm{Y}$ 处理播种期地 温与 CK 相近, 二者同一天出苗。拔节期地温表现为 $\mathrm{D}$ 处理 $>\mathrm{S}$ 处理 $>\mathrm{CK}>\mathrm{Y}$ 处理 $>\mathrm{J}$ 处理, 受地温影响, $\mathrm{D}$ 和 $S$ 处理玉米最早进入拔节期, 其次是 $\mathrm{CK}$ 和 $\mathrm{Y}$ 处 理, 最后是 $\mathrm{J}$ 处理。大喇叭口期, CK、Y 和 J 处理 5 25 $\mathrm{cm}$ 日平均地温均比拔节期高出 $3^{\circ} \mathrm{C}$ 以上, $\mathrm{D}$ 和 $\mathrm{S}$ 处 理分别比拔节期高出 $0.17^{\circ} \mathrm{C}$ 和 $0.15^{\circ} \mathrm{C}$ 。该生育时期 $\mathrm{D}$ 和 $\mathrm{S}$ 处理下玉米长势明显好于 $\mathrm{J} 、 \mathrm{Y}$ 处理和 $\mathrm{CK}$, 较 多和较大的叶片增强了单株玉米的光合作用, 利于 后期的生殖生长, 同时, 削弱了阳光对农田的照射, 降低了地温的增幅。 $\mathrm{D}$ 和 $\mathrm{S}$ 处理较 $\mathrm{CK}$ 提前 $12 \mathrm{~d}$ 进 入大喇叭口期, 其次是 $\mathrm{CK}$ 和 $\mathrm{Y}$ 处理, 最后是 $\mathrm{J}$ 处理,
说明该生育时期地温对玉米生育进程的影响减弱。 抽雄期 $\mathrm{S}$ 和 $\mathrm{D}$ 处理较 $\mathrm{CK}$ 提前 $8 \mathrm{~d}$, 且两处理均较 $\mathrm{CK}$ 提前 $11 \mathrm{~d}$ 成熟。 $\mathrm{J}$ 处理的抽雄期与大喇叭口期均 较 CK 晚 $2 \mathrm{~d}$, 晚于 CK $3 \mathrm{~d}$ 成熟。Y 处理与 CK 处理 的全生育期基本一致。整体来看, 受播种期和出苗 期地温影响, $\mathrm{S}$ 和 $\mathrm{D}$ 处理明显缩短了玉米的生育进程 (表 3 和图 4), 玉米各生育时期均较 CK 提前。

\section{3 对玉米干物质积累和穗部性状的影响}

在各生育时期, $\mathrm{S}$ 处理和 $\mathrm{D}$ 处理地上部单株干物 质量均显著 $(P<0.05)$ 高于 CK (表 4)。出苗期, 雨水充 足, 加之生物降解膜和塑料地膜的保温性明显好于 其他处理, 玉米的迅速生长为增产奠定了基础。抽 雄期, S 处理和 D 处理分别高出 CK $89.24 \mathrm{~g}$ 和 $91.19 \mathrm{~g}$; 成熟期, 分别高出 CK $120.90 \mathrm{~g}$ 和 $138.10 \mathrm{~g}$ 。在各生 育时期, $\mathrm{J}$ 处理和 $\mathrm{Y}$ 处理玉米地上部单株干重与 $\mathrm{CK}$ 差异均不显著 $(P>0.05)$ 。

$\mathrm{S}$ 处理和 $\mathrm{D}$ 处理穗长、穗粗、穗行数和行粒数 均显著 $(P<0.05)$ 优于 CK (表 5), 穗行数显著 $(P<0.05)$ 多于 $\mathrm{CK}$, 说明生物降解膜覆盖和塑料地膜覆盖可 以有效促进玉米穗部发育, 提高穗粒数。Y 处理玉米 的穗长、穗粗、穗行数、行粒数和籽粒出产率均与 $\mathrm{CK}$ 差异不显著 $(P>0.05)$ 。 $\mathrm{J}$ 处理穗粗和穗行数与 $\mathrm{CK}$ 差异不显著 $(P>0.05)$, 穗长、行粒数、百粒重和籽粒 出产率均显著 $(P<0.05)$ 低于 $\mathrm{CK}_{\text {。 }}$ 。

\section{4 对玉米产量及水分利用效率的影响}

$\mathrm{S}$ 处理和 $\mathrm{D}$ 处理通过提高穗粒数和百粒重而显 著 $(P<0.05)$ 提高了玉米籽粒产量, 较 $\mathrm{CK}$ 分别增产 


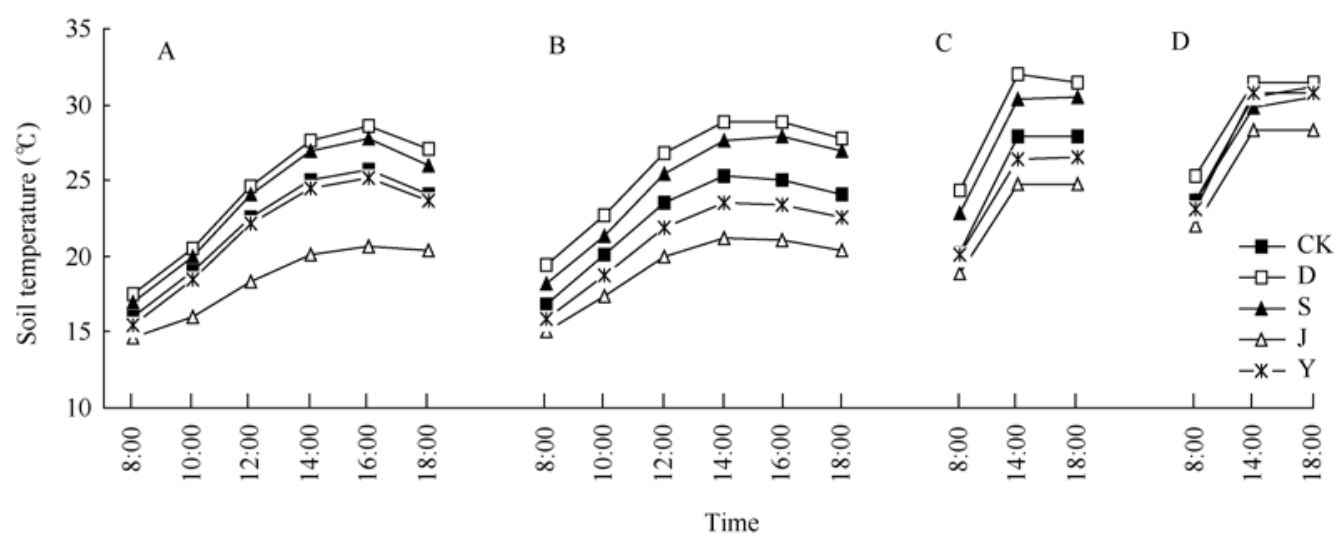

图 3 不同材料覆盖玉米播种期到大喇叭口期 5 25 cm 平均地温日变化

Fig. 3 Average temperature in 5-25 cm soil layer per day in different mulching treatments from sowing to bell-mouthing A：播种期; B：出苗期; C: 拔节期; D：大喇叭口期。CK：裸地平作; D: 塑料地膜覆盖; S: 生物降解膜覆盖; $\mathrm{J}$ : 玉米秸秆覆盖; Y: 液态膜覆盖。

A: Sowing; B: Emerging; C: Jointing; D: Bell-mouthing. CK: bare land; D: plastic film mulching; S: biodegradable film mulching; J: corn straw mulching; Y: liquid film mulching.

表 3 不同材料覆盖下玉米的生育进程

Table 3 Growth and development progresses of corn in different mulching treatments

\begin{tabular}{|c|c|c|c|c|c|c|c|c|c|c|c|c|c|}
\hline $\begin{array}{c}\text { 处理 } \\
\text { Treatment }\end{array}$ & $\begin{array}{c}\text { 播种期 } \\
\text { Sowing } \\
(\mathrm{M} / \mathrm{D})\end{array}$ & $\begin{array}{c}\text { 出苗期 } \\
\text { Emerging } \\
\text { (M/D) }\end{array}$ & $\begin{array}{c}\text {-裸地 } \\
-\mathrm{CK} \\
\text { (d) }\end{array}$ & $\begin{array}{c}\text { 拔节期 } \\
\text { Jointing } \\
\text { (M/D) }\end{array}$ & $\begin{array}{c}\text {-裸地 } \\
-\mathrm{CK} \\
\text { (d) }\end{array}$ & $\begin{array}{c}\text { 大喇叭口期 } \\
\text { Bell-mouthing } \\
\text { (M/D) }\end{array}$ & $\begin{array}{l}\text {-裸地 } \\
-\mathrm{CK} \\
\text { (d) }\end{array}$ & $\begin{array}{c}\text { 抽雄期 } \\
\text { Heading } \\
\text { (M/D) }\end{array}$ & $\begin{array}{c}\text {-裸地 } \\
-\mathrm{CK} \\
\text { (d) }\end{array}$ & $\begin{array}{c}\text { 成熟期 } \\
\text { Maturing } \\
\text { (M/D) }\end{array}$ & $\begin{array}{l}\text {-裸地 } \\
\text {-CK } \\
\text { (d) }\end{array}$ & $\begin{array}{c}\text { 全生育期 } \\
\text { Whole } \\
\text { growing } \\
\text { (d) }\end{array}$ & $\begin{array}{c}\text {-裸地 } \\
\text {-CK } \\
\text { (d) }\end{array}$ \\
\hline 裸地 CK & $4 / 26$ & $5 / 7$ & - & $6 / 6$ & - & $6 / 27$ & - & $7 / 17$ & - & $9 / 18$ & - & 145 & - \\
\hline 地膜 D & $4 / 26$ & $5 / 4$ & -3 & $5 / 28$ & -9 & $6 / 15$ & -12 & $7 / 9$ & -8 & $9 / 7$ & -11 & 134 & -11 \\
\hline 生膜 S & $4 / 26$ & $5 / 4$ & -3 & $5 / 28$ & -9 & $6 / 15$ & -12 & $7 / 9$ & -8 & $9 / 7$ & -11 & 134 & -11 \\
\hline 秸秆 J & $4 / 26$ & $5 / 8$ & 1 & $6 / 10$ & 4 & $6 / 29$ & 2 & $7 / 19$ & 2 & $9 / 21$ & 3 & 148 & 3 \\
\hline 液膜 Y & $4 / 26$ & $5 / 7$ & 0 & $6 / 6$ & 0 & $6 / 27$ & 0 & $7 / 17$ & 0 & $9 / 18$ & 0 & 145 & 0 \\
\hline
\end{tabular}

M/D: 月/日。缩写同表 1。M/D: month/day. Abbreviations as in Table 1.

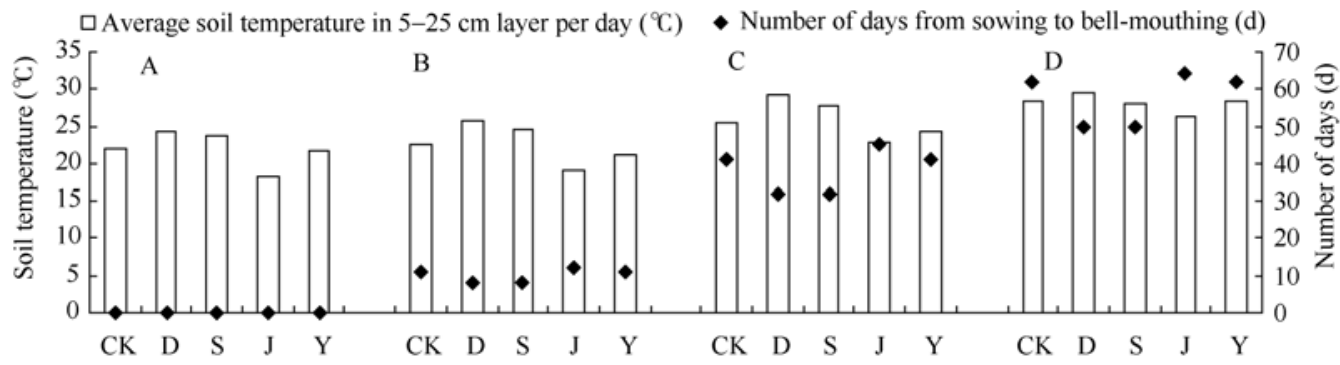

图 4 不同材料覆盖玉米播种期到大喇叭口期 5 25 cm 日平均地温与生育天数

Fig. 4 Average temperature in 5-25 cm soil layer per day and days of corn development in different mulching treatments from sowing to bell-mouthing

A：播种期; B：出苗期; C：拔节期; D：大喇叭口期。CK：裸地平作; D：塑料地膜覆盖; S: 生物降解膜覆盖;

$\mathrm{J}:$ 玉米秸秆覆盖; Y: 液态膜覆盖。

A: sowing; B: emerging; C: jointing; D: bell-mouthing. CK: bare land; D: plastic film mulching; S: biodegradable film mulching; $\mathrm{J}$ : corn straw mulching; Y: liquid film mulching.

26.9\%和 34.7\%; J 处理通过降低行粒数、百粒重和籽 粒出产率, 较 CK 减产 $10.5 \%$; Y 处理产量仅高出 CK $2.4 \%$ (表 6)。S 处理、D 处理的生物产量和产量水分 利用效率均显著 $(P<0.05)$ 高于其他处理, 较高的水 分利用效率成为增产的关键。 $\mathrm{J}$ 处理、 $\mathrm{Y}$ 处理和 $\mathrm{CK}$ 生物产量和水分利用效率差异不显著。4 种覆盖处 理均降低了玉米的经济系数, 其中 $\mathrm{J}$ 处理显著低于
CK (表 6)。

\section{3 讨论}

\section{1 覆盖对土壤水温环境的影响}

渭北旱塬不覆盖种植玉米生育期耗水量大于降 雨量, 往往造成土壤水分负增长, 严重影响其农业 生产水分环境和农业的持续发展。4 种不同材料覆 
表 4 不同材料覆盖下玉米各生育时期地上部单株干重

Table 4 Dry biomass of shoot in different mulching treatments in each developmental stage (g)

\begin{tabular}{|c|c|c|c|c|}
\hline 处理 & 出苗期 & 拔节期 & 抽雄期 & 成熟期 \\
\hline Treatment & Emerging & Jointing & Heading & Maturing \\
\hline 裸地 CK & $0.25 \pm 0.03 \mathrm{~b}$ & $7.19 \pm 3.69 \mathrm{~b}$ & $120.21 \pm 13.61 \mathrm{~b}$ & $273.80 \pm 31.04 \mathrm{~b}$ \\
\hline 地膜 D & $0.46 \pm 0.14 \mathrm{a}$ & $19.41 \pm 6.56 \mathrm{a}$ & $211.40 \pm 41.27 \mathrm{a}$ & $411.90 \pm 46.33 \mathrm{a}$ \\
\hline 生膜 S & $0.45 \pm 0.14 \mathrm{a}$ & $20.93 \pm 2.11 \mathrm{a}$ & $209.45 \pm 22.43 \mathrm{a}$ & $394.70 \pm 54.01 \mathrm{a}$ \\
\hline 秸秆 $\mathrm{J}$ & $0.20 \pm 0.06 \mathrm{~b}$ & $3.84 \pm 0.29 \mathrm{~b}$ & $95.76 \pm 4.89 \mathrm{~b}$ & $263.65 \pm 54.12 b$ \\
\hline 液膜 $\mathrm{Y}$ & $0.28 \pm 0.12 \mathrm{~b}$ & $7.40 \pm 1.02 \mathrm{~b}$ & $127.43 \pm 17.17 \mathrm{~b}$ & $284.08 \pm 42.54 \mathrm{~b}$ \\
\hline
\end{tabular}

缩写同表 1 。Abbreviations as in Table 1.

表 5 不同材料覆盖下玉米穗部性状和产量构成因素

Table 5 Ear characteristics and yield components of corn in different mulching treatments

\begin{tabular}{|c|c|c|c|c|c|c|}
\hline $\begin{array}{c}\text { 处理 } \\
\text { Treatment }\end{array}$ & $\begin{array}{c}\text { 穗长 } \\
\text { Ear length }(\mathrm{cm}) \\
\end{array}$ & $\begin{array}{c}\text { 穗粗 } \\
\text { Ear diameter }(\mathrm{cm})\end{array}$ & $\begin{array}{c}\text { 穗行数 } \\
\text { Rows per ear }\end{array}$ & $\begin{array}{c}\text { 行粒数 } \\
\text { Kernels per row }\end{array}$ & $\begin{array}{c}\text { 百粒重 } \\
\text { 100-kernel weight (g) }\end{array}$ & $\begin{array}{c}\text { 籽粒出产率 } \\
\text { Rate of production (\%) }\end{array}$ \\
\hline 裸地 CK & $17.8 \pm 2.7 \mathrm{c}$ & $5.00 \pm 0.38 \mathrm{~b}$ & $15.7 \pm 1.4 \mathrm{~b}$ & $31.1 \pm 6.2$ c & $33.00 \pm 1.10 \mathrm{~b}$ & $85.15 \pm 0.42 \mathrm{a}$ \\
\hline 地膜 D & $20.3 \pm 2.1 \mathrm{a}$ & $5.41 \pm 0.30 \mathrm{a}$ & $16.5 \pm 1.7 \mathrm{a}$ & $36.8 \pm 5.2 \mathrm{a}$ & $35.12 \pm 0.65$ а & $84.82 \pm 0.24 \mathrm{ab}$ \\
\hline 生膜 S & $19.6 \pm 1.9 \mathrm{~b}$ & $5.34 \pm 0.31$ a & $17.0 \pm 1.8 \mathrm{a}$ & $34.8 \pm 3.9 \mathrm{~b}$ & $33.75 \pm 1.44 \mathrm{~b}$ & $85.08 \pm 0.06 \mathrm{a}$ \\
\hline 秸秆 J & $17.1 \pm 2.4 \mathrm{~d}$ & $4.94 \pm 0.26 \mathrm{~b}$ & $15.5 \pm 1.6 \mathrm{~b}$ & $29.1 \pm 5.3 \mathrm{~d}$ & $30.37 \pm 1.06 \mathrm{~d}$ & $84.05 \pm 0.68 \mathrm{~b}$ \\
\hline 液膜 $\mathrm{Y}$ & $18.0 \pm 2.8 \mathrm{c}$ & $4.96 \pm 0.29 \mathrm{~b}$ & $15.6 \pm 1.6 \mathrm{~b}$ & $31.6 \pm 6.4 \mathrm{c}$ & $31.59 \pm 1.07$ c & $84.47 \pm 0.48 \mathrm{ab}$ \\
\hline
\end{tabular}

缩写同表 1 。Abbreviations as in Table 1.

表 6 不同材料覆盖下玉米产量及水分利用效率

Table 6 Yield of corn and WUE $E_{Y}$ in different mulching treatments

\begin{tabular}{|c|c|c|c|c|c|}
\hline $\begin{array}{c}\text { 处理 } \\
\text { Treatment }\end{array}$ & $\begin{array}{c}\text { 籽粒产量 } \\
\text { Yield }\left(\mathrm{kg} \mathrm{hm}^{-2}\right)\end{array}$ & $\begin{array}{c}\text { 增产 } \\
\text { Yield increase (\%) }\end{array}$ & $\begin{array}{c}\text { 生物产量 } \\
\text { Biomass }\left(\mathrm{kg} \mathrm{hm}^{-2}\right)\end{array}$ & $\begin{array}{c}\text { 经济系数 } \\
\text { Economic coefficient }\end{array}$ & $\begin{array}{c}\text { 产量水分利用效率 } \\
W E_{Y}\left(\mathrm{~kg} \mathrm{~mm}^{-1} \mathrm{hm}^{-1}\right)\end{array}$ \\
\hline 裸地 CK & $7136.3 \pm 384.7 \mathrm{~b}$ & - & $13552.9 \pm 1536.4 \mathrm{~b}$ & $0.54 \pm 0.03 \mathrm{a}$ & $18.16 \pm 1.20 \mathrm{~b}$ \\
\hline 地膜 D & $9611.3 \pm 388.5$ a & 34.7 & $20389.3 \pm 2293.3 \mathrm{a}$ & $0.52 \pm 0.01 \mathrm{abc}$ & $24.00 \pm 0.81 \mathrm{a}$ \\
\hline 生膜 S & $9054.4 \pm 774.4 \mathrm{a}$ & 26.9 & $19537.8 \pm 2673.3 \mathrm{a}$ & $0.52 \pm 0.01 \mathrm{abc}$ & $23.25 \pm 1.19 \mathrm{a}$ \\
\hline 秸秆 J & $6385.5 \pm 486.9 \mathrm{~b}$ & -10.5 & $13050.9 \pm 2679.1 \mathrm{~b}$ & $0.51 \pm 0.02 \mathrm{c}$ & $17.49 \pm 0.99 \mathrm{~b}$ \\
\hline 液膜 $\mathrm{Y}$ & $7305.4 \pm 667.4 \mathrm{~b}$ & 2.4 & $14062.1 \pm 2105.8 \mathrm{~b}$ & $0.53 \pm 0.05 \mathrm{ab}$ & $19.20 \pm 1.97 \mathrm{~b}$ \\
\hline
\end{tabular}

缩写同表 1 。WUE : water use efficiency of yield. Other abbreviations as in Table 1.

盖的对比研究表明, 玉米成熟期, 生物降解膜和塑 料地膜覆盖土壤䛎水量显著 $(P<0.05)$ 低于对照, 说 明这两种覆盖增加了对土壤的水分消耗, 可能会影 响后茬作物的底墑, 雨养农区长期地膜覆盖可能造 成土壤水分生产力开始衰减。这从土壤水分环境方 面阐释了薛菁芳等 ${ }^{[10]}$ 的研究结果“地膜覆盖到一定 年限后生物产量和经济产量开始呈现下降趋势”产 生的原因。玉米出苗期, 植株需水较少, 覆盖处理主 要通过抑制蒸发达到保墑效果。4 种材料覆盖处理的 0 40 $\mathrm{cm}$ 土壤含水量均显著 $(P<0.05)$ 高于裸地种植, 利于出苗和前期的营养生长, 不同覆盖材料处理 $0 \sim 40 \mathrm{~cm}$ 土壤平均含水量为 $\mathrm{J}$ 处理 $>\mathrm{S}$ 处理 $>\mathrm{Y}$ 处理 $>\mathrm{D}$ 处理 $>C K$ 。拔节期, $0 \sim 80 \mathrm{~cm}$, 各覆盖处理之间及与 对照土壤含水量均无明显差异。进入抽雄期和灌浆 期后, 玉米生长消耗水分加快, 不同覆盖处理间土
壤水分出现较大差异, 40 160 cm, 秸秆覆盖处理土 壤平均含水量显著 $(P<0.05)$ 高于对照和其他覆盖处 理。生物降解膜和塑料地膜覆盖处理对较深土层 $(60 \sim 120 \mathrm{~cm})$ 的水分利用加强。Laboski 等 ${ }^{[11]}$ 研究表 明, 玉米 85\%的根系分布在 0 30 cm 土层, 而玉米 根系发育的最适地温为 $20 \sim 24^{\circ} \mathrm{C}$, 本研究从播种到 出苗期, $\mathrm{S}$ 处理和 $\mathrm{D}$ 处理 0 $25 \mathrm{~cm}$ 平均地温 $\left(24.1^{\circ} \mathrm{C}\right.$ 和 $\left.25.0^{\circ} \mathrm{C}\right)$ 分别比对照 $\left(22.3^{\circ} \mathrm{C}\right)$ 高 $8.2 \%$ 和 $12.3 \%$, 有效促 进了玉米的出苗和根系发育。土壤水温协同作用, 缩短了玉米的生育进程, 这在不同的生产区域和土 壤类型下具有一致的效果 ${ }^{[12-15]}$ 。张冬梅等 ${ }^{[16]}$ 研究发 现地膜覆盖提高了土壤温度, 生育期明显提前, 但 在玉米抽雄前后遭受重伏旱, 会影响玉米正常授粉, 最终导致玉米严重减产。这与本研究结果并不一致, 可能是试验期间的降雨分布及降雨量不同所致。本 
研究表明, 生物降解膜增温保墑效果与塑料地膜接 近, 关于以上两种地膜使用对耕地长期墑情和地力 的影响差异尚需进一步探索。

秸秆覆盖在玉米成熟期, $0 \sim 200 \mathrm{~cm}$ 土壤平均含 水量 $(16.64 \%)$ 显著 $(P<0.05)$ 高于对照 $(15.61 \%) 、$ 生物 降解膜 (13.93\%)和塑料地膜(13.52\%)覆盖处理, 高 出液态膜 (16.06\%) 处理 $3.6 \%$ ，显著提高了旱地 0 200 $\mathrm{cm}$ 的土壤贮水量(较对照增加 $28.32 \mathrm{~mm}$ ), 为 后茬作物提供了良好底墒。鲁向晖等 ${ }^{[17]}$ 研究发现, 秸秆覆盖处理比对照在作物根系分布密度较大的范 围 0 80 cm 深度对降水敏感程度高, 可以把水分保 蓄在作物较易利用的深度。本研究表明, 在玉米生 长前期和后期, 秸秆覆盖对降水表现出不同的敏感 程度。玉米生育前期, 秸秆覆盖主要提高了 0 100 $\mathrm{cm}$ 土层土壤含水量, 玉米生育中后期, 主要提高下 层 100 200 cm 土壤含水量。虽然秸秆覆盖提高了土 壤含水量, 但从播种到出苗期, $0 \sim 25 \mathrm{~cm}$ 平均地温低 于对照 15.8\%, 严重影响了玉米出苗和前期生长。进一 步证明秸秆覆盖会造成不同程度的低温效应 ${ }^{[18-19]}$ 。拔 节期到灌浆期是玉米需水最多的阶段, 这一阶段秸 秆覆盖使 $0 \sim 200 \mathrm{~cm}$ 土壤平均含水量明显高于其他 覆盖处理, 但由于受前期地温偏低的影响, 玉米最 后的籽粒产量仍低于不覆盖处理。不同灌水量(3750 $\mathrm{m}^{3} \mathrm{hm}^{-2} 、 3000 \mathrm{~m}^{3} \mathrm{hm}^{-2}$ 和 $2250 \mathrm{~m}^{3} \mathrm{hm}^{-2}$ )下种植玉米 的研究 ${ }^{[15]}$ 表明, 在年均气温 $14.1^{\circ} \mathrm{C}$ 的地区, 秸秆覆 盖在全生育期总灌水量 $3000 \mathrm{~m}^{3} \mathrm{hm}^{-2}(300 \mathrm{~mm})$ 下较 不覆盖增产 $35.86 \%$ 。本试验秸秆覆盖处理全生育期 有效降雨 $351.1 \mathrm{~mm}$, 却造成减产, 可能主要与试验 区域热量条件限制(年均气温 $10.5^{\circ} \mathrm{C}$ )有关。

本研究表明, 液态膜覆盖增强了玉米主要生育 阶段浅层土壤的咜水能力, 这与李彩霞等 ${ }^{[20]}$ 研究结 果一致。崔欢虎等 ${ }^{[21]}$ 研究表明, 液态膜使冬小麦水 分利用效率提高 22\%以上, 在小麦抽穗期 $5 \mathrm{~cm}$ 土层 日平均地温增高 $2.9^{\circ} \mathrm{C}$ 左右。本研究液态膜使玉米水 分利用效率提高 5.7\%, 在玉米播种至大喇叭口期 5 $\mathrm{cm}$ 土层日平均地温增高 $1.2^{\circ} \mathrm{C}$, 与冬小麦研究结论 相似, 但使该生长阶段 5 25 cm 土层平均地温降低, 在较深土层并未表现出显著的增温保墑效果。

\section{2 对玉米生长和产量的影响}

大量研究表明地膜覆盖具不同程度的增产效 果 ${ }^{[14,22-23]}$ 。本研究表明, 生物降解膜和塑料地膜覆盖 种植玉米显著 $(P<0.05)$ 提高出苗期至成熟期的地上 部干重以及穗长、穗粗、行粒数、产量和水分利用
效率。塑料地膜覆盖促进玉米生长和增产的作用虽 高于生物降解膜覆盖, 但玉米地上部干重、穗粗、 行粒数、经济产量、生物产量和水分利用效率均无 显著 $(P<0.05)$ 差异。两种覆盖使玉米全生育期较对照 提前 $11 \mathrm{~d}$, 避免了生育后期可能出现的干旱 ${ }^{[24]}$ 。从 环保角度考虑，降解膜的使用相对于露地种植起到 较好保温、保墑及增产的作用，是解决农业种植“白 色污染”的有效途径 ${ }^{[25]}$ 。

已有研究 ${ }^{[26-28]}$ 表明, 秸秆覆盖种植玉米表现不 同程度的增产。本研究结果表明, 秸秆覆盖处理显 著 $(P<0.05)$ 降低了玉米穗长、行粒数、百粒重和经济 系数。主要受地温和物理阻碍等因素影响, 秸秆覆 盖使玉米营养生长不充分, 进而影响生殖生长, 造 成减产。这从作物生长的角度, 进一步证明了高亚 军等 ${ }^{[29]}$ 提出的“旱地农田秸秆覆盖具有改善土壤水 分条件、调节土壤温度的作用, 但可能会出现作物 减产”的结论。

液态膜覆盖种植玉米显著 $(P<0.05)$ 增加了百粒 重, 籽粒产量略高于对照, 并未达到显著差异。而李 彩霞等 ${ }^{[20]}$ 指出, 中、低水分(灌水量分别为 $300 \mathrm{~mm}$ 、 $225 \mathrm{~mm})$ 的液膜覆盖处理的产量和水分利用效率较 对照显著增加，增产 $35.4 \%$ 以上，灌溉水的利用效率 也提高 $35.7 \%$ 以上。这说明液态膜覆盖种植玉米在不 同的气候区域增产效果需进行深入研究。

\section{4 结论}

在渭北旱塬区, 生物降解膜、塑料地膜和液态 膜覆盖种植玉米均促进增产, 提高水分利用效率, 玉米营养生长阶段 5 25 cm 平均地温分别提高 1.4 ${ }^{\circ} \mathrm{C} 、 2.6^{\circ} \mathrm{C}$ 和降低 $0.8^{\circ} \mathrm{C}$ 。秸秆覆盖造成玉米减产，水 分利用效率降低，营养生长阶段 5 25 cm 低温效应 明显(平均地温降低 $3.0^{\circ} \mathrm{C}$ )。4 种覆盖处理均不同程 度降低了玉米的经济系数。玉米全生育期内, 秸秆 覆盖处理 0 200 cm 土壤平均含水量高于裸地、塑料 地膜覆盖、生物降解膜覆盖和液态膜覆盖, 并随着 玉米的生长保墒效果得到加强, 在前期主要表现在 0 100 cm 土层, 后期主要表现在 100 200 cm 土层。 生物降解膜和塑料地膜覆盖的保墑效果主要表现在 玉米营养生长阶段的浅层土壤。生物降解膜和塑料 地膜覆盖均使玉米全生育期提前 $11 \mathrm{~d}$, 通过延长大 喇叭口期至抽雄期的时间，延长了营养生长时间， 相对缩短了生殖生长时间。秸秆覆盖种植玉米使全 生育期延长 $3 \mathrm{~d}$, 液态膜覆盖种植玉米不影响生育进 
程。综合产量及长期土壤水分环境效应, 旱塬秸秆 覆盖种植玉米技术在渭北具有可行性和应用价值。

\section{References}

[1] Du S-N(杜社妮), Bai G-S(白岗栓). Studies on effects of plastic film mulching on soil environment of maize field. Agric Res Arid Areas (干旱地区农业研究), 2007, 25(5): 56-59 (in Chinese with English abstract)

[2] Ma S-Q(马树庆), Wang Q(王琪), Guo J-P(郭建平), Shen Z-S(沈 钟声). Geographical change law of effects of corn plastic mulching on increasing temperature and production in Northeast China. Trans CSAE (农业工程学报), 2007, 23(8): 66-71 (in Chinese with English abstract)

[3] Zhang D-Q(张德奇), Liao Y-C(廖允成), Jia Z-K(贾志宽). Research advances and prospects of film mulching in arid and semi-arid areas. Agric Res Arid Areas (干旱地区农业研究), 2005, 23(1): 208-213 (in Chinese with English abstract)

[4] Zhang J(章剑). Study on different degradable film. Anhui Agric Sci Bull (安徽农学通报), 2005, 11(3): 23 (in Chinese)

[5] Yang Y-J(杨玉姣), Huang Z-B(黄占斌), Yan Y-M(闯玉敏), Liu $\mathrm{M}$ (刘敏), Zhu Q(朱强). Effects on temperature and moisture of soil and seeding of maize to biodegradable film coverage. $J$ Agro-Environ Sci (农业环境科学学报), 2010, 29(suppl): 10-14 (in Chinese with English abstract)

[6] Zhao A-Q(赵爱琴), Li Z-Z(李子忠), Gong Y-S(龚元石). Effects of biodegradable mulch film on corn growth and its degradation in field. J China Agric Univ (中国农业大学学报), 2005, 10(2): 74-78 (in Chinese with English abstract)

[7] Wu Y-Q(吴涌泉), Qu M(屈明), Sun F(孙芬), Chen Z-F(陈祖富). Effect of straw mulching on soil physical and chemical properties, soil microorganism and environment. Chin Agric Sci Bull (中国 农学通报), 2009, 25(14): 263-268 (in Chinese with English abstract)

[8] Lu X-H(鲁向晖), Sui Y-Y(隋艳艳), Wang F(王飞), Mu X-M(穆 兴民). Study on soil water status of maize s fallow under straw mulch in dryland. J Arid Land Resour Environ (干旱区资源与环 境), 2008, 22(3): 156-159 (in Chinese with English abstract)

[9] Qiang X-M(强小嫚), Zhou X-G(周新国), Li C-X(李彩霞), Guo D-D(郭冬冬), Liu Z-G(刘祖贵), Zhang J-P(张俊鹏). Effect of liquid film mulching on growth and yield of summer maize under different soil moisture conditions. Trans CSAE (农业工程学报), 2010, 26(1): 54-60 (in Chinese with English abstract)

[10] Xue J-F(薛菁芳), Wang J-K(汪景宽), Li S-Y(李双异), Zhu F-C(祝凤春), Chen S-Q(陈书强). Studies on changes of corn biomass yield and its components under the condition of long-term plastic film-mulching and fertilization. J Maize Sci (玉 米科学), 2006, 14(5): 66-70 (in Chinese with English abstract)

[11] Laboski C A M, Dowdy R H, Allmara R R, Lamb J A. Soil strength and water content influences on corn root distribution in a sandy soil. Plant Soil, 1998, 203: 239-247

[12] Wu B-Z(吴伯志), Liu L-G(刘立光), Zheng Y(郑毅), Xia Z-Y(夏
振远). Effect on red soil erosion ratio by different cultivation measure. Gengzuo Yu Zaipei (耕作与栽培), 1996, (5): 17-20 (in Chinese)

[13] Zhai Z-F(翟治芬), Zhao Y-Z(赵元忠), Jing M(景明), Zhang $\mathrm{J}-\mathrm{H}($ 张建华). Evapotranspiration characteristics of spring maize under mulch film and staw cover. J Shandong Agric Univ (Nat Sci Edn) (山东农业大学学报·自然科学版), 2010, 41(2): 209-215 (in Chinese with English abstract)

[14] Wang X(王金金)，Xu G-B(胥国斌)，Ren Z-G(任志刚)，Zhang Z-J(张占军), Jian Y-F(简毓峰), Zhang Y-M(张永明). Effects of environment-friendly degradable films on corn growth and soil environment. Chin J Eco-Agric (中国生态农业学报), 2007, 15(1): 78-81 (in Chinese with English abstract)

[15] Zhang J-P(张俊鹏), Sun J-S(孙景生), Liu Z-G(刘祖贵), Gao $\mathrm{Y}$ (高阳). Effect of moisture and mulching on filling characteristics and yield of summer maize. Chin J Eco-Agric (中国生态农 业学报), 2010, 18(3): 501-506 (in Chinese with English abstract)

[16] Zhang D-M(张冬梅), Chi B-L(池宝亮), Huang X-F(黄学芳), Liu E-K(刘恩科), Zhang J(张健). Analysis of adverse effects on maize yield decrease resulted from plastic film mulching in dryland. Trans CSAE (农业工程学报), 2008，24(4)：99-102 (in Chinese with English abstract)

[17] Lu X-H(鲁向晖), Gao P(高鹏), Wang F(王飞), Sui Y-Y(隋艳艳), $\mathrm{Mu} \mathrm{X}-\mathrm{M}$ (穆兴民). Effect of straw mulch on yield and water utilization of spring maize in the south mountainous area of Ningxia. Chin J Soil Sci (土壤通报), 2008, 39(6): 1248-1251 (in Chinese with English abstract)

[18] Xu L(徐澜), An W(安伟), Hao J-P(郝建平). The effect of water-osmosis plastic membrane on physiology, yield component and yield for drought maize. J Arid Land Resour Environ (干旱 区资源与环境), 2010, 24(8): 180-185 (in Chinese with English abstract)

[19] Chen S-Y(陈素英), Zhang X-Y(张喜英), Pei D(裴冬), Sun $\mathrm{H}-\mathrm{Y}$ (孙宏勇). Effects of corn straw mulching on soil temperature and soil evaporation of winter wheat field. Trans CSAE (农业工 程学报), 2005, 21(10): 171-173 (in Chinese with English abstract)

[20］Li C-X(李彩霞), Zhou X-G(周新国), Qiang X-M(强小嫚), Guo D-D(郭冬冬), Liu Z-G(刘祖贵), Zhang J-P(张俊鹏). Effects of liquid film mulching on soil moisture, temperature and yield of summer maize field under different water conditions. J Maize Sci (玉米科学), 2010, 18(3): 108-112 (in Chinese with English abstract)

[21] Cui H-H(崔欢虎), Jing H(靖华), Zhao H-Z(赵海桢), Zhang $\mathrm{J}-\mathrm{L}$ (张俊灵), Wang J(王笳). Ecological effects of black fluid-film mulched over in dry land winter wheat. Chin J Eco-Agric (中国 生态农业学报), 2006, 14(1): 73-75 (in Chinese with English abstract)

[22] Li J-Q(李建奇). The mechanism study of the influences of plastics film mulch on grain yield and seed quality of spring maize. $J$ Maize Sci (玉米科学), 2008, 16(5): 87-92 (in Chinese with Eng- 
lish abstract)

[23] Duan D-Y(段德玉), Liu X-J(刘小京), Li W-Q(李伟强), Li $\mathrm{C}-\mathrm{Z}$ (李存桢). The ecological effects of plastic-mulched culture on the summer maize. Agric Res Arid Areas (干旱地区农业研 究), 2003, 21(4): 6-9 (in Chinese with English abstract)

[24] Huang Z-D(黄志德), Wang A-N(王安宁). Cultivation technology and yield increasing theory of corn. Agron Technol Serv (农技服 务), 2009, 26(6): 11 (in Chinese)

[25] Zhang K-M(张开敏), Li J-R(李进荣). Study on different degradable film in the same corn field. Yunnan Agric Sci Technol (云南农业科技), 2010, (3): 30-32 (in Chinese)

[26] Liu C(刘超), Wang Y-K(汪有科), Zhan J-W(湛景武), Yang $\mathrm{Z}-\mathrm{Y}$ (杨直毅). The influence of straw mulch amount to summer maize yield. J Irrig Drainag (灌溉排水学报), 2008, 27(4): 64-66 (in Chinese with English abstract)

[27] Bu Y-S(卜玉山), Miao G-Y(苗果园), Shao H-L(邵海林), Wang J-C(王建程). Analysis of growth and development and yield of corn mulched with plastic film and straw. Acta Agron Sin (作物 学报), 2006, 32(7): 1090-1093 (in Chinese with English abstract)

[28] Hong X-Q(洪晓强), Zhao E-L(赵二龙), Song H-W(宋宏伟). Effects of stubble mulching on the field on cropland soil moisture content and spring corn growth. Chin Agric Sci Bull (中国农学通 报), 2005, 21(8): 177-179 (in Chinese with English abstract)

[29] Gao Y-J(高亚军), Li S-X(李生秀). Cause and mechanism of crop yield reduction under straw mulch in dryland. Trans CSAE (农业 工程学报), 2005, 21(7): 15-19 (in Chinese with English abstract) 